Research Article

\title{
Study on the Hydrogen Generation Rules of Coal Oxidation at Low Temperature
}

\author{
Shao He ${ }^{1, *}$, Zhou Fubao ${ }^{1}$, Chen Kaiyan ${ }^{1}$, Cheng Jianwei ${ }^{1}$ and Melogh, Palu H. ${ }^{2}$ \\ ${ }^{I}$ China University of Mining \& Technology, Xuzhou, Jiangsu, 221008, China \\ ${ }^{2}$ Developemnt and Exploration Center for Power Technology, CCEP Co., Ltd., Dortmund, Germany
}

Received 1 February 2014; Accepted 30 July 2014

\begin{abstract}
Based on a hydrogen desorption experiment and a comparative experiment of low-temperature coal oxidation performed prior to and after hydrogen desorption, this paper demonstrates the occurrence of hydrogen adsorption in coal at room temperature and reveals that the hydrogen generated in the process of coal oxidation originates from coal oxidation and desorption. The results show that the hydrogen accumulation generated only by coal oxidation and the hydrogen accumulation generated solely by desorption both exhibit a LangmuirEXT1 function equation relationship with temperature. The result of the present research can provide a theoretical basis for the accurate prediction of spontaneous coal combustion and is of great significance to the prevention and control of coal spontaneous combustion in coal mines, industrial coal storage and transportation.
\end{abstract}

Keywords: Low Temperature Oxidation; Hydrogen; Desorption; Adsorption; LangmuirEXT1 Equation

\section{Introduction}

With the extensive application of fully mechanized caving, fire in coal mines is a serious problem for the coal industry. In coal mines, most fires occur due to spontaneous combustion because of excessive coal residue in the goaf and severe air leakage, etc. [1]. Currently, $\mathrm{CO}, \mathrm{C}_{2} \mathrm{H}_{4}$ and $\mathrm{C}_{2} \mathrm{H}_{2}$ are commonly used as index gases to monitor spontaneous coal combustion, but few studies have examined the variation of hydrogen as an index gas in the process of coal spontaneous combustion. Vered Nehemia et al.[2] believed that oxidized bituminous coal can release $\mathrm{H}_{2}$ when the temperature ranges from $40^{\circ} \mathrm{C}$ to 115 and identified that the hydrogen generation mechanism proceeded via the intermediate product formaldehyde. S. L. Grossman et al. [3], [4], [5], [6] conducted an oxidation experiment on different coal samples within a temperature range of 55 to 95 and found that coal could produce $\mathrm{H}_{2}$ at low temperatures during the oxidation process and that the temperature positively correlated with the amount of $\mathrm{H}_{2}$ generated. Cohen and Haim [7] also found that bituminous coal could generate $\mathrm{H}_{2}$ during the oxidation process at a room temperature of 40 and that the amount of $\mathrm{H}_{2}$ is in direct proportion to the amount of $\mathrm{O}_{2}$ consumed. Liang $\mathrm{H}$. D proposed [8] that coal could release hydrogen molecules at room temperature, and Dai G. L [9] analyzed the hydrogen source in goaf. The China University of Mining and Technology (Beijing) [10] identified a relationship between methane and the hydrogen and helium naturally released by coal. Hydrogen in coal exists in the form of small molecules such as alkanes, hydroxide radicals, carboxyls as well as in branched chains of the aromatic nucleus structure, which is very unstable and can be produced under the effect of thermal shock [11]. When a coal fire occurs, alkane compounds decompose, lose their hydrogen atoms and produce alkene compounds after heating up. However, the product of $\mathrm{H}$ free radicals is highly unstable and easily integrates other $\mathrm{H}$ radicals into molecular hydrogen. The article by $\mathrm{Li}$ et al. introduced the generation mechanism of hydrogen during coal combustion [12], [13]. Vered Nehemia[2] considered that the most probable hydrogen producing reactions during spontaneous coal combustion could be considered as follows:

$\mathrm{Coal}+\mathrm{O}_{2} \rightarrow$ Oxycoal or Surface Oxides

Oxycoal $\rightarrow \mathrm{CO}_{2}+\mathrm{H}_{2} \mathrm{O}+\mathrm{Q}_{2}$ (major reaction)

Oxycoal $\rightarrow \mathrm{H}_{2}, \mathrm{CO}, \mathrm{C}_{1-5}$ (accompanying side reactions)

Surface Oxides $\rightarrow \mathrm{CH}_{2} \mathrm{O}$

$2 \mathrm{CH}_{2} \mathrm{O}+\mathrm{O}_{2} \rightarrow 2 \mathrm{CO}_{2}+2 \mathrm{H}_{2}$

Zhou F. B et al.[14] proposed a three-stage hydrogen generation model during reignition in a fire zone(as shown in Fig.1). 


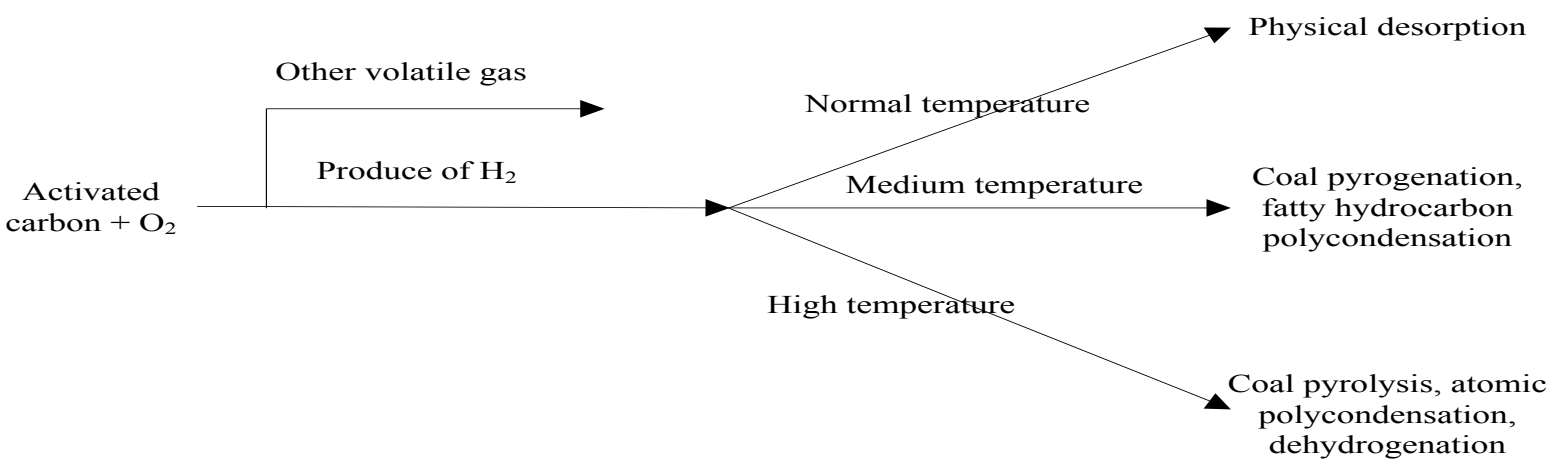

Fig. 1. Three-stage hydrogen generation model during reignition in fire zone

Fig.1 showed that the hydrogen absorbed in coal was discharged into the surrounding atmosphere in small quantities after desorption in the first stage under normal temperature or natural conditions with temperature below $150^{\circ} \mathrm{C}$,

As an important product of coal oxidation at low temperatures, the emergence and variation of $\mathrm{H}_{2}$ is connected to spontaneous coal combustion. Existing studies of the origin of $\mathrm{H}_{2}$ are not systematic and exhaustive. Therefore, a systematic analysis of the variation of $\mathrm{H}_{2}$ in coal oxidation at low temperatures is important to improve and establish a gas index system for the prediction, prevention and control of coal spontaneous combustion.

\section{Experimental Installation}

To investigate the variation of hydrogen in the spontaneous coal combustion process, a systematic desorption and coal oxidation experiment system was established. As shown in Fig.2, the system consists of a temperature-programmed oven, gas supply system, reaction vessel (coal sample jar), temperature measurement and control system and gas chromatograph. The temperature-programmed oven provides the heating environment for the experiment and ensures the uniformity of the internal temperature field. The gas supply system mainly offers oxygen and nitrogen for coal oxidation and desorption at low temperature in the reaction vessel. The coal sample jar connects the gas supply circuit, the temperature measurement system and the gas vent path. The gas chromatograph detects the types and contents of gases. A 60-m copper pipe was also installed between the gas inlet and the gas supply pipeline as a gas preheating circuit.

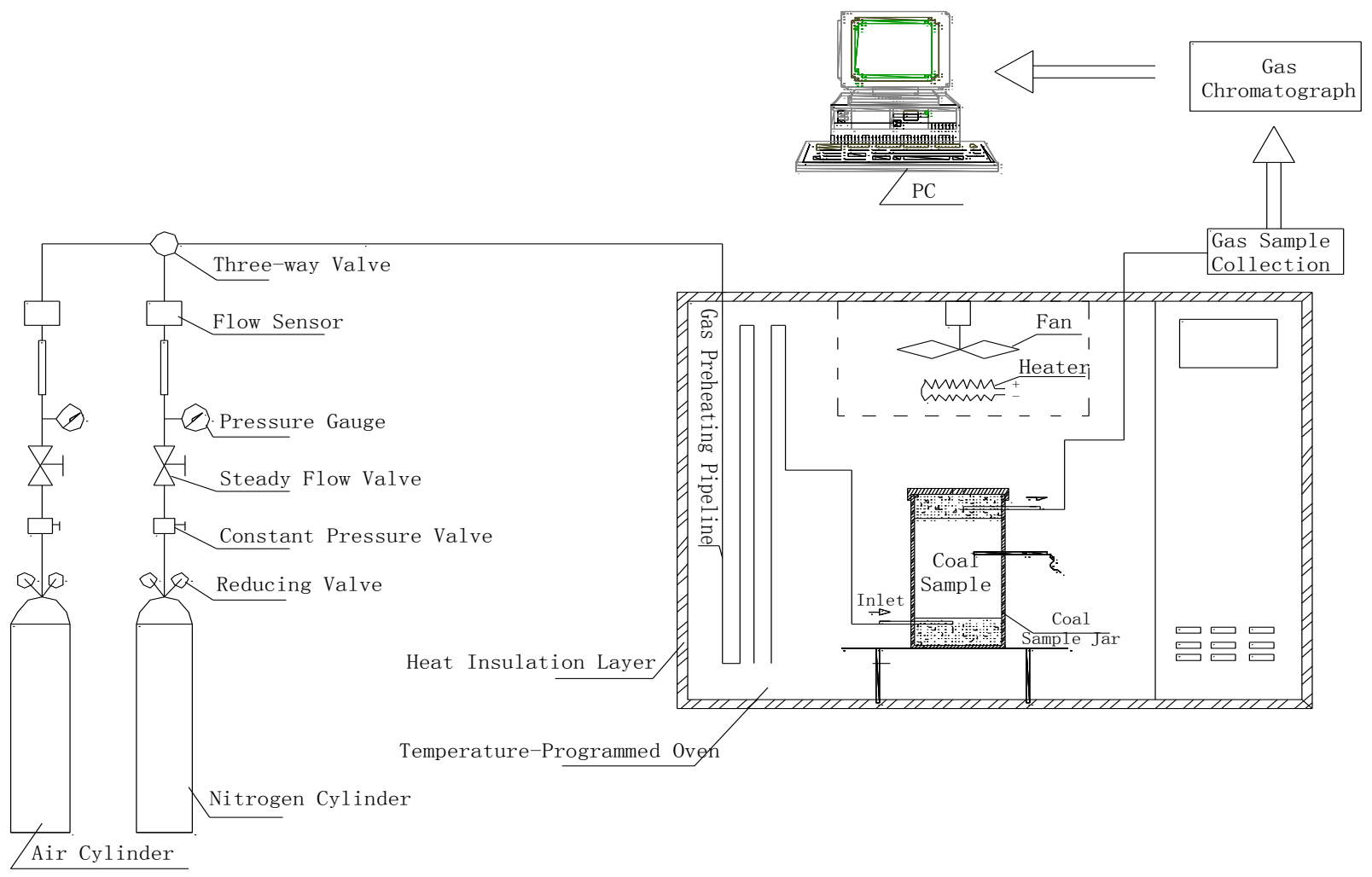

(a) Experiment system 
Shao He, Zhou Fubao, Chen Kaiyan, Cheng Jianwei and Melogh, Palu H.

JJournal of Engineering Science and Technology Review 7 (3) (2014) 90 - 95

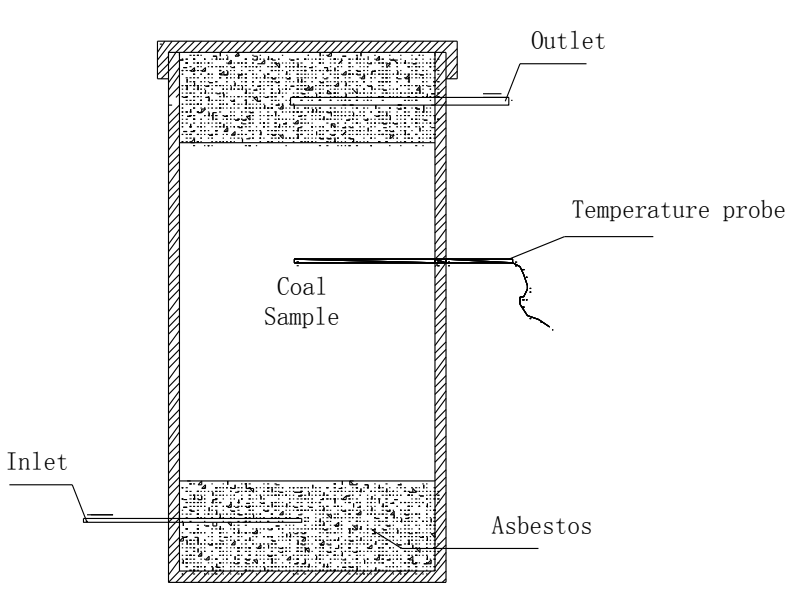

(b) Coal sample jar

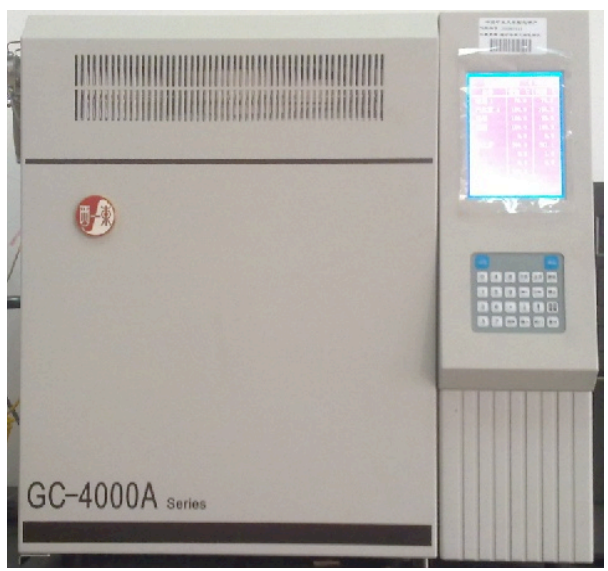

(d) Gas chromatograph

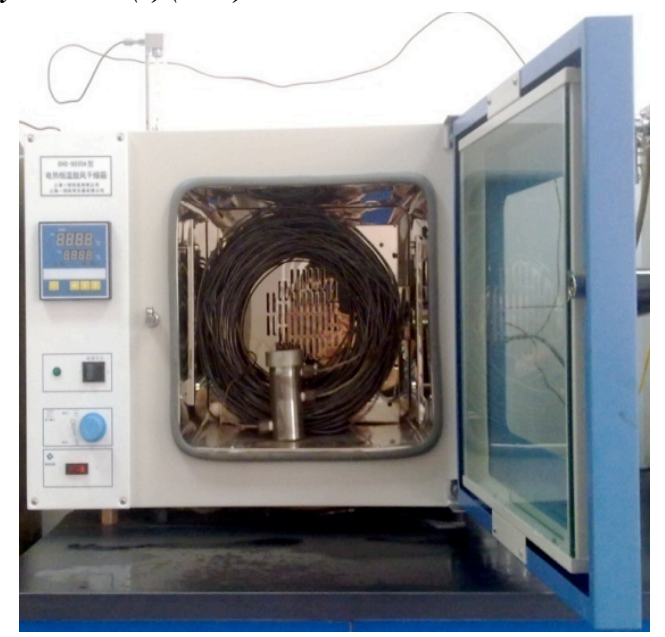

(c) Temperature-programmed Oven

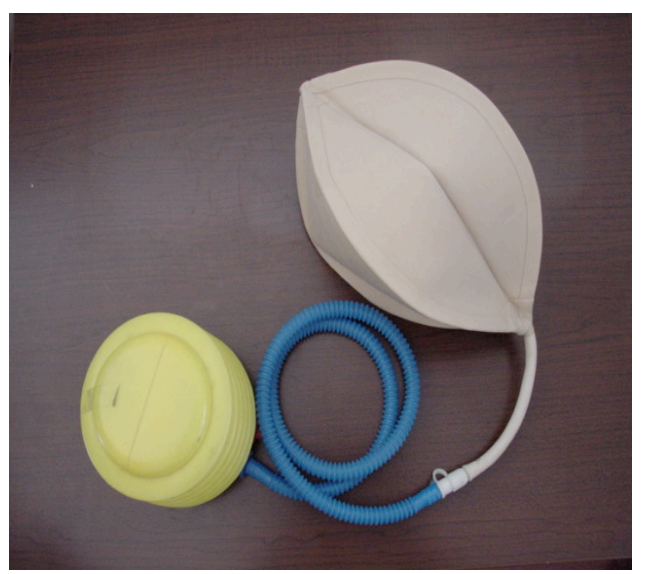

(e) Bladder of sampling ball

Fig. 2. Integrated test system of temperature programmed for coal spontaneous combustion and desorption

\section{Experimental Procedure}

3\# coal samples from the Dongtan Coal Mine of Yanzhou Coal Mining Company and $1 \#$ and $6 \#$ coal samples from the Cuijiazhai Coal Mine in the Kailuan, Yuzhou mine area were selected as experimental coal samples. Prior to the experiment, the oxide layers on the surfaces of coal samples were stripped, and the coal samples were then crushed and ground. Finally, 25-g particles with a diameter between 40 and 60 were selected as the experimental coal samples. The proximate analysis of coal is shown in Table 1 . The test device for proximate analysis is shown in Fig.3.

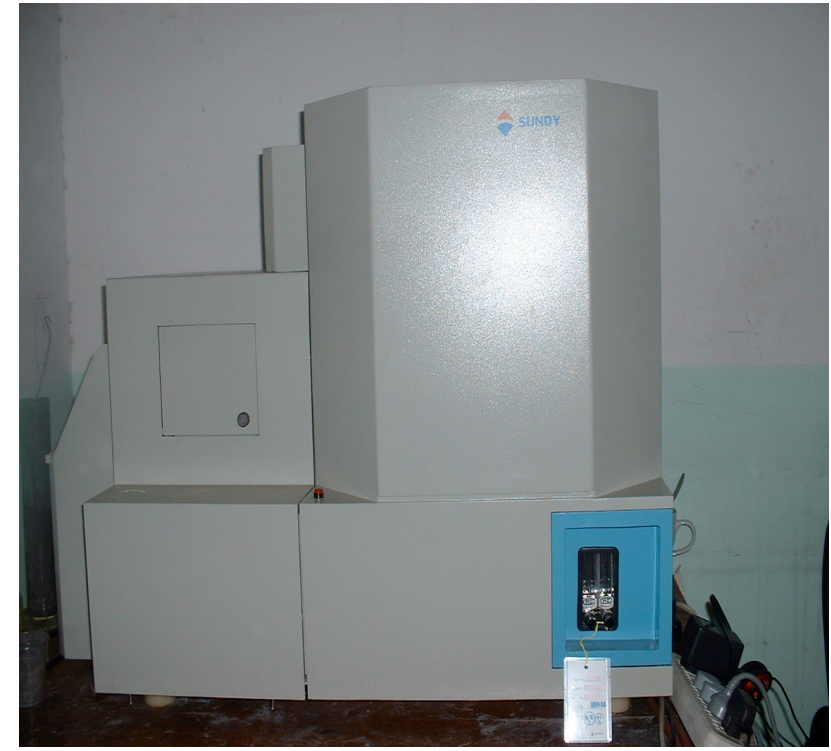

Fig. 3. Test device for proximate analysis of coal 
Shao He, Zhou Fubao, Chen Kaiyan, Cheng Jianwei and Melogh, Palu H.

/Journal of Engineering Science and Technology Review 7 (3) (2014) 90 - 95

Tab. 1. Results of proximate analysis of coal

\begin{tabular}{ccccc}
\hline Coal Sample & $\begin{array}{c}\mathbf{M}_{\text {ad }}(\% \\
)\end{array}$ & $\begin{array}{c}\mathbf{V}_{\text {ad }}(\% \\
\mathbf{A}_{\text {ad }}(\%\end{array}$ & $\left.\begin{array}{c}\mathbf{F C}_{\text {ad }}(\%) \\
\%\end{array}\right)$ \\
\hline $\begin{array}{c}\text { 3\# Coal } \\
\text { from } \\
\text { Dongtan } \\
\text { Coal Mine } \\
\text { 1\# Coal } \\
\text { from }\end{array}$ & 3.11 & 39.45 & 8.92 & 48.52 \\
$\begin{array}{c}\text { Cuiajiazhai } \\
\text { Coal Mine } \\
\text { 6\# Coal } \\
\text { from }\end{array}$ & 19.84 & 32.10 & 6.01 & 42.05 \\
$\begin{array}{c}\text { Cuijiazhai } \\
\text { Coal Mine }\end{array}$ & 18.76 & 29.02 & & \\
\hline
\end{tabular}

\subsection{Desorption of Adsorbed Hydrogen}

The jar containing the coal samples was placed into the temperature programmed oven, and the flow of nitrogen was regulated to $200 \mathrm{ml} / \mathrm{min}$. The gas chromatograph was then used to analyze the composition of the gases. When oxygen could no longer be detected in the coal sample jar, the temperature control oven was set to 105 , and the coal samples were heated to the same temperature under a steady nitrogen supply. The desorption of adsorbed hydrogen was initiated and continued in the coal samples until hydrogen could no longer be detected. The temperature programmed oven was then closed to cool the internal temperature to room temperature.

The desorption experiment aimed to eliminate the influence of moisture and ensured that there $\mathrm{H}_{2}$ was not adsorbed on the coal samples during the coal oxidation experiment.

\subsection{Oxidation at Low Temperature and Collection of Gas Samples}

The valve of the air cylinder was opened, and dry air containing $21 \%$ oxygen was infused into the coal sample jar at a flow rate of $150 \mathrm{ml} / \mathrm{min}$. The temperature-programmed oven was then set to 200 to heat and oxidize the coal samples. The gas samples were then collected and analyzed at intervals of 15 when the temperature of the coal samples was lower than 100 and at intervals of 20 when the temperature of coal samples exceeded 100 .

\subsection{Experimental Results}

During the desorption experiment at a temperature of 105 in the temperature-programmed oven, hydrogen was continuously detected in the reaction vessel; however, hydrogen could no longer be detected after approximately 24 hours of desorption. Therefore, $\mathrm{H}_{2}$ definitely adsorbed on the coal. The hydrogen generation without desorption in the oxidation experiment, $q_{\text {total }}$, includes two parts, namely the $\mathrm{H}_{2}$ adsorbed on coal, $q_{\text {desorption }}$, and the $\mathrm{H}_{2}$ generated by coal oxidation, qoxidation. The amount of $\mathrm{H}_{2}$ desorption can be defined as the difference between the hydrogen $q_{\text {total }}$ and $q_{\text {oxidation }}$ at the same temperature, i.e., $q_{\text {total }}=q_{\text {desorption }}+q_{\text {oxidation }}$. Let $Q_{\text {oxidation }}, Q_{\text {total }}$ and $Q_{\text {desorption }}$ be the accumulation of $q_{\text {oxidation }}, q_{\text {total }}$ and $q_{\text {desorption }}$ with respect to temperature.

\section{Results Analysis}

4.1 $\mathrm{H}_{2}$ Generated by Coal Oxidation without Desorption Fig.4 shows the relationship between the hydrogen generated by coal oxidation at low temperature $\left(q_{\text {total }}\right)$ without desorption and the coal temperature. Fig. 5 shows the relationship between the hydrogen accumulated $\left(Q_{\text {oxidation }}\right)$ by coal oxidation and the temperature; Fig.6 shows the relationship between the hydrogen accumulated $\left(Q_{\text {total }}\right)$ without desorption and the temperature; Fig.7 shows the relationship between the hydrogen accumulated $\left(Q_{\text {desorption }}\right)$ by coal desorption and the temperature.

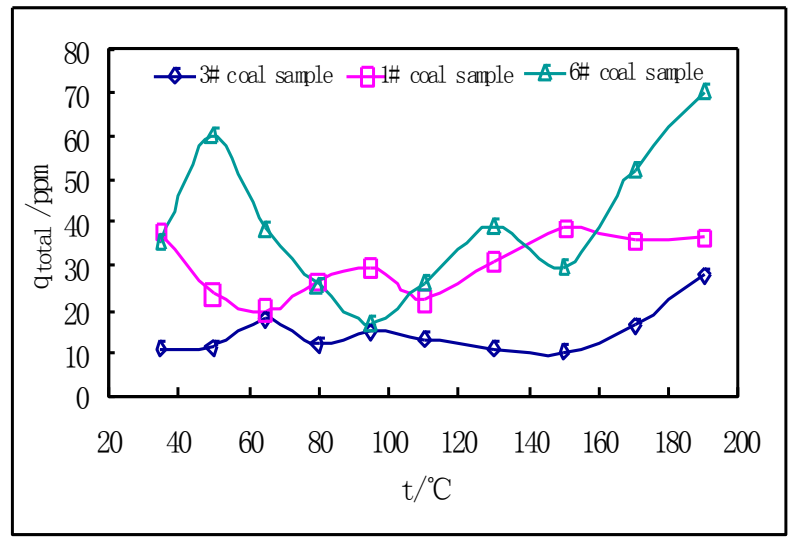

Fig. 4. $\mathrm{H}_{2}$ generated by the oxidation of coal without desorption

Fig. 4 shows that the $\mathrm{H}_{2}$ generated by the coal oxidation without desorption $\left(q_{\text {total }}\right)$ did not relate to the temperature for the three types of coal samples studied. Furthermore, $q_{\text {total }}$ does not linearly correlate with changes in the temperature. Thus, $\mathrm{H}_{2}$ cannot be directly used as a gas indicator to predict spontaneous coal combustion.

\section{2 $Q_{\text {oxidation }}$ of $\mathrm{H}_{2}$ Accumulation by Coal Oxidation}

Fig. 5 shows that that the $\mathrm{H}_{2}$ accumulated due to coal oxidation after desorption, $Q_{\text {oxidation, }}$ positively correlates with the temperature, and the fitting relationship between $Q_{\text {oxidation }}$ and temperature obeys LangmuirEXT1 function model, whose the parameter values are shown in table 2 .

The $Q_{\text {oxidation }}$ of the $6 \#$ coal sample from the Cuijiazhai Mine exhibits a "concave" relationship with the temperature, with a demarcation point at 110 . Q Q oxidation increases more rapidly as the temperature increases from $35 \sim 110$, while $Q_{\text {oxidation }}$ varies slowly as the temperature increases and finally approaches a stable value when the temperature is within the range of $110 \sim 190$. For the $3 \#$ coal sample from the Dongtan Coal Mine and 1\# coal sample from the Cuijiazhai Coal Mine, $Q_{\text {oxidation }}$ slowly increases as the temperature increases from $35 \sim 110$, while $Q_{\text {oxidation }}$ varies rapidly as the temperature increases from $110 \sim$ 190 .

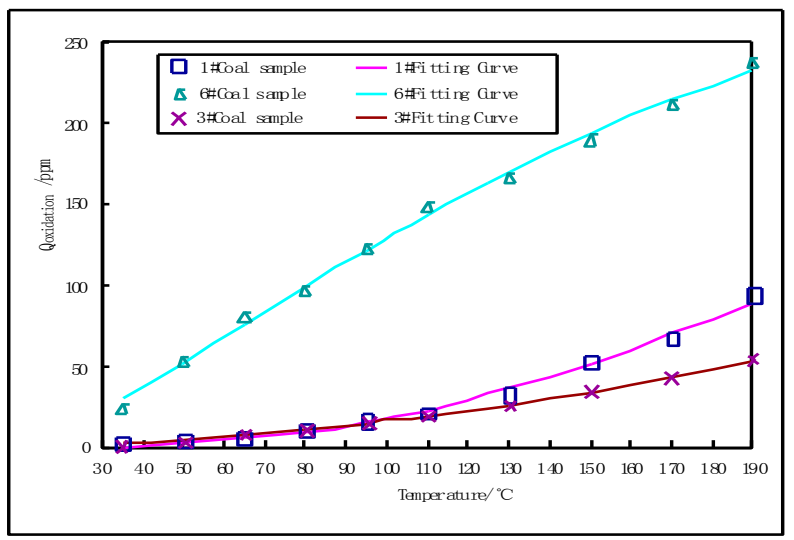

Fig. 5. Relationship between $Q_{\text {oxidation }}$ generated by coal oxidation and temperature 
Shao He, Zhou Fubao, Chen Kaiyan, Cheng Jianwei and Melogh, Palu H.

/Journal of Engineering Science and Technology Review 7 (3) (2014) 90 - 95

Tab. 2. Fitting function between $Q_{\text {oxidation }}$ and temperature

Model

LangmuirEXT1

\begin{tabular}{|c|c|c|c|c|}
\hline \multirow[t]{2}{*}{ Function } & \multicolumn{4}{|c|}{$y=\frac{a \cdot b \cdot x^{1-c}}{1+b \cdot x^{1-c}}$} \\
\hline & $\mathrm{a}$ & $\mathrm{b}$ & $\mathrm{c}$ & $\mathrm{R} 2$ \\
\hline $\begin{array}{l}\text { 1\#coal } \\
\text { sample }\end{array}$ & 265.871 & $5.68 \mathrm{E}-08$ & -2.04665 & 0.99396 \\
\hline $\begin{array}{l}\text { 6\#coal } \\
\text { sample }\end{array}$ & 695.64024 & $3.61 \mathrm{E}-04$ & -0.39335 & 0.99567 \\
\hline $\begin{array}{l}3 \# \text { coal } \\
\text { sample }\end{array}$ & $\begin{array}{c}5848.1453 \\
8\end{array}$ & $\begin{array}{c}4.40229 \mathrm{E}- \\
7\end{array}$ & -0.89457 & 0.98605 \\
\hline
\end{tabular}

\section{3 $Q_{\text {total }}$ of $\mathrm{H}_{2}$ Accumulation without Desorption}

As shown in Fig.6, the $Q_{\text {total }}$ includes not only the hydrogen generated by coal desorption but also by coal oxidation. $Q_{\text {total }}$ increases with the temperature, and the relationship between $Q_{\text {total }}$ and temperature obeys the LangmuirEXT1 function model, as shown in table 3. Fig.6 shows that the $Q_{\text {total }}$ for coal desorption and oxidation smoothly varies with the increasing temperature; it does not show an obvious demarcation point.

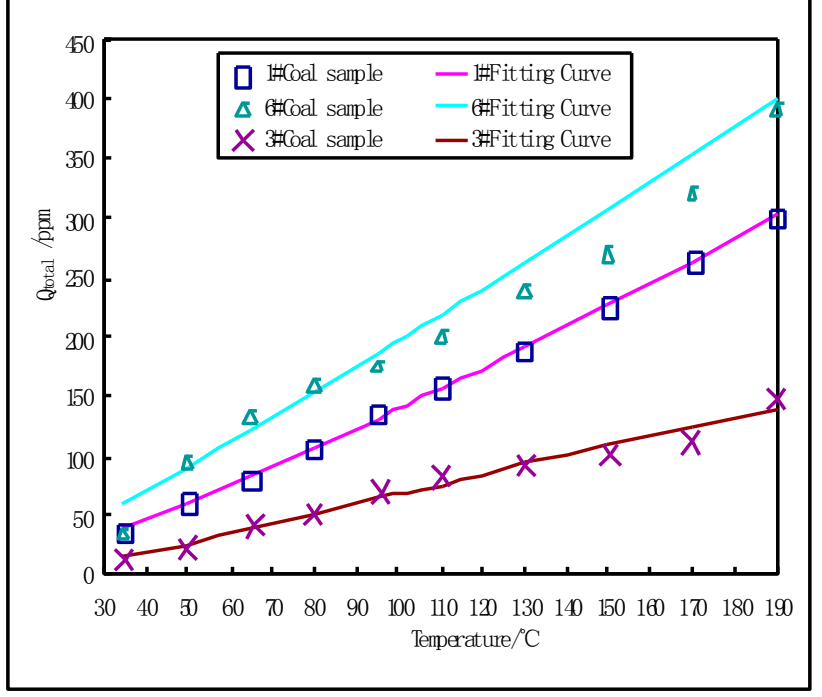

Fig.6. Relationship between $Q_{\text {total }}$ excluding desorption and temperature

Tab.3. Fitting function about $Q_{\text {total }}$ excluding desorption and temperature

\begin{tabular}{|c|c|c|c|c|}
\hline Model & \multicolumn{4}{|c|}{ LangmuirEXT1 } \\
\hline \multirow{3}{*}{ Function } & \multirow{2}{*}{\multicolumn{4}{|c|}{$y=\frac{a \cdot b \cdot x^{1-c}}{1+b \cdot x^{1-c}}$}} \\
\hline & & & & \\
\hline & $\mathrm{a}$ & $\mathrm{b}$ & $\mathrm{c}$ & $\mathrm{R}^{2}$ \\
\hline $\begin{array}{l}\text { 1\#Coal } \\
\text { sample }\end{array}$ & 7103.8919 & $6.93 \mathrm{E}-05$ & -0.23126 & 0.99948 \\
\hline $\begin{array}{l}\text { 6\#Coal } \\
\text { sample }\end{array}$ & 313048.4175 & $1.35 \mathrm{E}-06$ & -0.31407 & 0.98530 \\
\hline $\begin{array}{l}\text { 3\#Coal } \\
\text { sample }\end{array}$ & 375.04539 & $1.82958 \mathrm{E}-4$ & -0.54042 & 0.98334 \\
\hline
\end{tabular}

\section{4 $Q_{\text {desorption }}$ of $\mathrm{H}_{2}$ Accumulation Generated by Coal Desorption}

Fig.7 and table 4 reveal that the fitting relationship between $Q_{\text {desorption }}$ and temperature obeys the LangmuirEXT1 function model, i.e., $Q_{\text {desorption }}$ positively correlates with the temperature. The values of the parameters are shown in table 4. For the $3 \#$ coal sample from the Dongtan Coal Mine and $1 \#$ coal sample from the Cuijiazhai Coal Mine, $Q_{\text {desorption }}$ is a convex function of temperature, with 95 as the demarcation point. When the temperature is below 95, $Q_{\text {desorption }}$ increases quickly, while it increases slowly above 95.

The properties of the LangmuirEXT1 function indicate that a maximum exists in the "convex" type function, i.e., $\max \left(Q_{\text {desorption }}\right)=\mathrm{a}$. The Langmuir adsorption model for $\mathrm{CH}_{4}$ adsorbed in coal is assumed as follows: within a certain adsorption system, a dynamic equilibrium can be established between adsorption and desorption. By adopting this hypothesis, the physical meaning of $\max \left(Q_{\text {desorption }}\right)=\mathrm{a}$ can be described as the maximum desorption of $\mathrm{H} 2$ with an increase in the temperature for a given quality of coal sample.

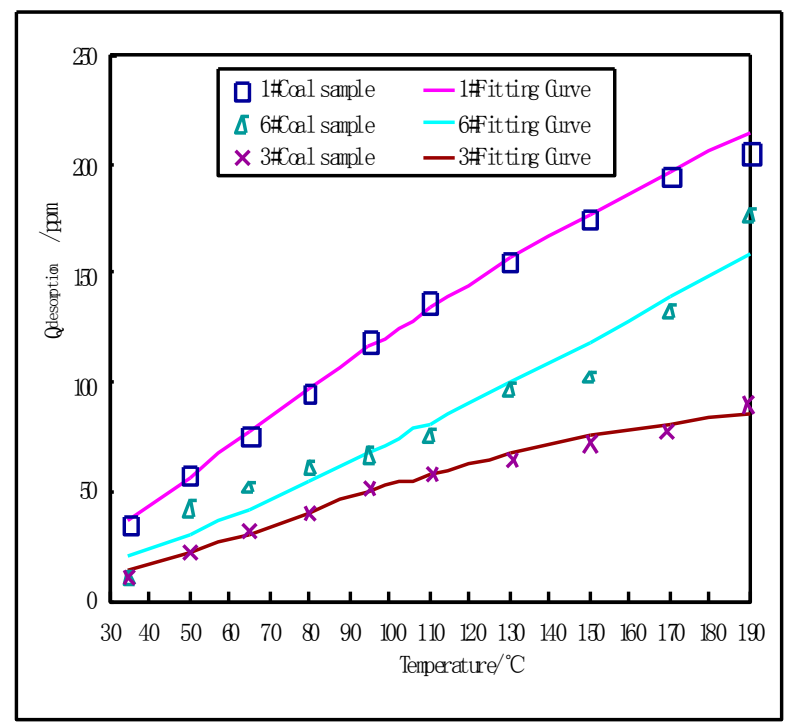

Fig. 7. Relationship between $Q_{\text {desorption }}$ and temperature

Tab. 4. Fitting function about $Q_{\text {desorption }}$ and temperature

\begin{tabular}{ccccc}
\hline \multirow{2}{*}{ Model } & \multicolumn{4}{c}{ LangmuirEXT1 } \\
\hline \multirow{2}{*}{ Function } & \multicolumn{4}{c}{$y=\frac{a \cdot b \cdot x^{1-c}}{1+b \cdot x^{1-c}}$} \\
\cline { 2 - 5 } & $\mathrm{a}$ & $\mathrm{b}$ & $\mathrm{c}$ & $\mathrm{R}^{2}$ \\
\hline \multirow{2}{*}{ 1\#Coal sample } & 464.4509 & $6.77 \mathrm{E}-04$ & -0.36024 & 0.99604 \\
& & & & \\
& & & & \\
6\#Coal sample & 337043.0867 & $7.15 \mathrm{E}-09$ & -1.13563 & 0.93565 \\
& & & & \\
\hline
\end{tabular}




\section{Conclusions}

From the above analysis, the following conclusions can be drawn as follows:

(1) According to the experimental results, this paper demonstrates the adsorption of hydrogen in coal at room temperature and proposes two methods to generate hydrogen during coal oxidation at low temperature $-q_{\text {desorption }}$ generated by the desorption of the hydrogen adsorbed to coal and $q_{\text {oxidation }}$ generated by coal oxidation.

(2) The hydrogen accumulation generated by coal oxidation $\left(Q_{\text {oxidation }}\right)$ and desorption $\left(Q_{\text {desorption }}\right)$, and the $Q_{\text {tatal }}$ all conform to the LangmuirEXT1 function relationship is shown as follow:

$$
y=\frac{a \cdot b \cdot x^{1-c}}{1+b \cdot x^{1-c}}
$$

The curves are "concave", "smooth", and "convex", respectively and 95 is the demarcation point in the "concave" and "convex" types.
(3) Based on the LangmuirEXT1 function, the relationship between hydrogen generation and temperature, $\mathrm{H}_{2}$ can be used as the indicator gas to predict spontaneous coal combustion in order to improve the gas index system of spontaneous combustion prediction. The results provide a theoretical basis for the prevention and control of spontaneous coal combustion in coalmines, open coal yards and industrial coal transportation.

\section{Acknowledgments}

This work is financially supported by grants from the Fundamental Research Funds for Central Universities (Grant No. 2013QNA01), the National Science Foundation of China (Grant No.51304203) and the Natural Science Foundation of Jiangsu Province of China for Youths (Grant No. BK20130191); the authors are grateful for these supports.

\section{References}

1. Ashok K. Singh; R.V.K. Singh; Mahendra P. Singh; Hem Chandra; N.K. Shukla,"Mine fire gas indices and their application to Indian underground coal mine fires", International Journal of Coal Geology, 69, 2007, pp. 192-204.

2. Vered Nehemia; Shoshana Davidi; Haim Cohen,"Emission of hydrogen gas from weathered steam coal piles via formaldehyde as a precursor I. Oxidative decomposition of formaldehyde catalyzed by coal - batch reactor studies", Fuel, 78,1999, pp. 775-780.

3. S. L. Grossman; S. Davidi; Haim Cohen; "Explosion risks during the confined storage of bituminous coals-Calculation of gaseous hydrogen accumulation in ship", Fuel, 74(12), 1995, pp. 17721775.

4. S. L. Grossman; Ina Wegener; Wolfgang Wanzl, "Molecular hydrogen evolution as a consequence of atmospheric oxidation of coal: 3. Thermo gravimetric flow reactor studies" Fuel, 73(5), 1994, pp. $762-767$

5. S. L. Grossman; Shoshana Davidi; Haim Cohen, "Evolution of molecular hydrogen during the atmospheric oxidation of coal", Fuel, 70(7), 1991, pp. 897-898.

6. S. L. Grossman; Shoshana Davidi; Haim Cohen, "Molecular hydrogen evolution as a consequence of atmospheric oxidation of coal: 1. Batch reactor simulations", Fuel, 72(2), 1993, pp. 193-197.

7. Cohen; Haim, "Molecular hydrogen formed via low temperature oxidation of bituminous coals as the source of explosions in underground coal mines" // 25th Annual International Pittsburgh Coal Conference, PCC-Proceedings. USA: CSREA Press, 2008.
8. Liang H. D. "Emission of Molecular Hydrogen from Coal $-\mathrm{A}$ Security related Phenomenon for Coal Transportation and Production", Mining Safety \& Environmental Protection, 28(2), 2001, pp. 1-3. (In Chinese)

9. Dai G. L, Zhang G. S, Shao H., "Study on Relationship between Hydrogen and Oxidization and Spontaneous Combustion of Coal in Gobs in Xinji Coal Mine", Coal Engineer, 1998 (2), pp. 12-15. (In Chinese)

10. Zhou Q, Jiang H. Q, Liang H. D., "Analysis of the Hydrogen Release from Coalbed Gas, Southern QinShui Basin", Nature Gas Geoscience, 17(6), 2007, pp,. 871-873. (In Chinese)

11. Qi W, Zhang L, Zhang L, Shu X Q, Ding Z J, Li G. "Research progress of coal to hydrogen by way of catalytic decomposition process", China Coal, 33(10), 2003, pp. 57-58. (In Chinese)

12. Li Z H, Lin B Q, Zhang L Q, Pan S K, He Y H. "Effects of hydrogen production on gas explosion", Journal of China University of Mining \& Technology, 37(2), 2008, pp. 147-151. (In Chinese)

13. Sun X X, Chen J Y. "The Physical and Chemical Basis of Pulverized Coal", Wuhan: Huazhong University of Science and Technology Press, 1991.(In Chinese)

14. Zhou F. B, Li J. H, Liu Y.S, Shao H. "Rules of variation in hydrogen during reignition of underground fire zones of spontaneous coal combustion", Mining Science and Technology, 20(4), 2010, pp. 499-503. 